The successor to the journal Music Review, Nineteenth-Century Music Review aims to locate music within the widest possible framework of intellectual activity pertaining to the long nineteenth century (c.1789-1914). It particularly welcomes interdisciplinary scholarship that explores music within the context of other artistic and scientific discourses. Articles with fine visual or iconographic content are encouraged, as are those rich in musically illustrative material. Articles accepted for publication will reflect a diversity of critical viewpoints.

\title{
Contents of Volume 7, Issue 2
}

Articles

Roberta Montemorra Introduction to the Special Issue on Ottocento Opera

Marvin

Denise Gallo

'Repatriating' Falstaff: Boito, Verdi and Shakespeare (in Translation)

Susan Rutherford

From Byron's The Corsair to Verdi's // corsaro:

Poetry Made Music

Andreas Giger

Behind the Police Chief's Closed Doors: The Unofficial Censors of Verdi in Rome

Alexandra Wilson Music, Letters and National Identity:

Reading the 1890s' Italian Music Press

Book Reviews

CD Reviews

Score Reviews

Published in association with the Centre for Nineteenth-Century Music, Durham University, UK

Cover illustration: The Production of Verdi's Falstaff at Milan.

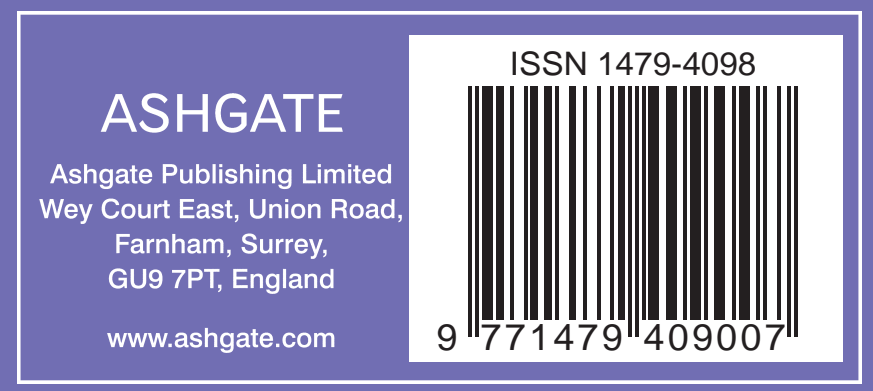

